\title{
Feasible and simple exclusion criteria for pulmonary reference populations
}

\author{
Ane Johannessen, Ernst R Omenaas, Geir Egil Eide, Per S Bakke, Amund Gulsvik
}

Thorax 2007;62:792-798. doi: 10.1136/thx.2006.071480

See end of article for authors' affiliations

Correspondence to: Dr Ane Johannessen, Centre for Clinical Research, Haukeland University Hospital, N-5021 Bergen, Norway; Ane.

Johannessen@helse-bergen. no

Received 7 September 2006 Accepted 7 February 2007 Published Online First 27 March 2007
Background: International guidelines recommend that pulmonary reference populations consist of neversmokers without respiratory diseases or symptoms, but the diseases and symptoms are not clearly specified. The present study aimed to identify simple exclusion criteria for defining pulmonary reference populations. Methods: Based on a random sample from a general population (the parent population), 2358 subjects aged 26-82 years performed spirometric tests. From this sample, subjects were stepwise excluded according to self-reported obstructive lung diseases, symptoms and smoking history. Four increasingly more healthy respiratory reference populations were formed. Prediction equations for the median and lower limit of normal lung function were derived using quantile regression analysis.

Results: Subjects without self-reported obstructive lung diseases or the cardinal respiratory symptoms of breathlessness, cough or wheeze (population B), never-smokers without cardinal symptoms (population C) and never-smokers without any respiratory symptoms (population D) constituted 50\% ( $n=1184), 23 \%$ $(n=539)$ and $14 \%(n=331)$ of the parent population (population A), respectively. The largest discrepancy between prediction equations was found between the parent population and the population without cardinal respiratory symptoms (population $B)(p<0.05)$. Minor changes in the reference equations were also seen when excluding ever-smokers (population C). There was no additional change with exclusion of other respiratory symptoms (population D). Age-related decline in lung function was steepest in the parent population.

Conclusions: Obstructive lung diseases, smoking history, breathlessness, cough and wheeze are optimal exclusion criteria for a pulmonary reference population. Further validation of the exclusion criteria identified in this study is recommended with identical wording in other and larger multinational populations.
A ccording to recommendations from the American Thoracic Society (ATS), reference values for normal lung function should be derived from lifetime non-smokers free of respiratory diagnoses and symptoms. ${ }^{1}$ The newly released joint guidelines from the ATS and the European Respiratory Society (ERS) also support these recommendations. ${ }^{2}$ The general nature of such recommendations results in various interpretations regarding exactly which respiratory symptoms should be excluded from a reference population.

During the last 30 years, numerous reference values for normal lung function have been published..$^{3-17}$ Although they have all been estimated on the basis of healthy reference populations, the definition of a healthy population has varied from study to study. There is therefore considerable variation in the relative size and characteristics of reference populations. No previous study has assessed the implications of different definitions of reference populations for pulmonary prediction equations in a general population.

The existing literature shows an association between reduced forced expiratory volume in $1 \mathrm{~s}\left(\mathrm{FEV}_{1}\right)$ and the respiratory symptoms of wheeze, breathlessness and cough. ${ }^{18-21}$ Chronic phlegm, on the other hand, has in some surveys not been associated with airflow obstruction or reduced $\mathrm{FEV}_{1}$ levels, ${ }^{19}$ suggesting that perhaps not all respiratory symptoms need to be accounted for in a healthy reference population used for derivation of reference values.

The main objective of our study was to identify simple exclusion criteria for defining pulmonary reference populations. We compared pre-bronchodilator reference values derived from population samples representing increasingly healthier and narrower reference population definitions with regard to respiratory status.

\section{METHODS \\ Subjects}

The present study was based on the second phase of the Hordaland County Cohort Study. Information on sampling procedures and data collection in this longitudinal epidemiological study has been reported previously. ${ }^{22}{ }^{23}$ Briefly, the baseline survey population was a random sample of the general adult population in Western Norway in 1985 within the age range 15-70 years. All adults in the study area were eligible for inclusion. A random sample of the population was drawn by Statistics Norway and invited to participate in the first phase of the Hordaland County Cohort Study. Based on the first phase in 1985, 2358 subjects of those eligible for follow-up (74\%) participated in a second phase in 1996-7 comprising both questionnaires and spirometry. The questionnaires contained detailed questions on disease history, respiratory symptoms, occupational exposure to airborne agents, smoking history and educational level. Standing height without shoes was measured at the spirometric examination to the nearest centimetre. Weight was measured with light indoor clothing to the nearest $0.5 \mathrm{~kg}$.

\section{Respiratory disorders and smoking habits}

The participants reported the presence or absence of 15 respiratory diseases and symptoms in a self-administered questionnaire (see Appendix in online supplement available at http://thorax.bmj.com/supplemental). The items in the questionnaire originated from the British Medical Research Council questionnaire (BMRC), the Norwegian Respiratory

Abbreviations: $\mathrm{FEV}_{1}$, forced expiratory volume in $1 \mathrm{~s} ; \mathrm{FVC}$, forced vital capacity; LLN, lower limit of normal 
Questionnaire (NRQ) and from the European Community Respiratory Health Survey questionnaire (ECRHS). ${ }^{24-28}$

Subjects were classified as current smokers, ex-smokers and never-smokers according to self-reported daily smoking habits. Self-reported smoking habits in this population have been previously validated by carboxyhaemoglobin measurements of venous blood samples with an OSM3 Hemoximeter (Radiometer, Copenhagen, Denmark). ${ }^{29} 30$ Occupational exposure to airborne agents was defined as an affirmative answer to the question "Have you ever had a work-place with much dust or fumes in the air?".

\section{Spirometric testing}

Pre-bronchodilator forced vital capacity (FVC) and $\mathrm{FEV}_{1}$ were measured with a dry wedge spirometer (Vitalograph S-model) according to the ATS criteria. ${ }^{31}$ The spirometer was calibrated each morning and afternoon with a 1 litre syringe. The participants were seated and wearing nose clips, and received standardised instructions from the laboratory technician. At least three

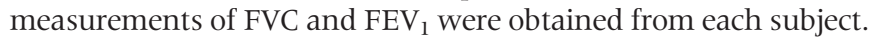
The spirometric test was satisfactory when the two highest FVC measurements differed from each other by $<300 \mathrm{ml}$. The highest $\mathrm{FVC}$ and $\mathrm{FEV}_{1}$ values were used in the $\mathrm{FEV}_{1} / \mathrm{FVC}$ ratio regardless of whether or not they came from the same trial. Room temperatures ranged from 19 to $24^{\circ} \mathrm{C}$ with a mean (SD) of $22(0.5)^{\circ} \mathrm{C}$.

\section{Statistical analyses}

Starting with the general study population (the parent population), four increasingly healthy respiratory reference populations were formed. These population types were obtained stepwise by excluding subjects based on the presence of numerous respiratory characteristics (obstructive lung diseases, respiratory symptoms and smoking history). The initial exclusion order of these characteristics was based on both clinical and methodological considerations. For each step, $t$ tests were performed to assess whether mean lung function differed between subjects who had this characteristic and the remaining population who did not have this characteristic. If the $t$ test was significant $(p \leqslant 0.05)$, subjects with the characteristic in question were excluded from the population before moving on to analysis of the next respiratory characteristic.

After identifying population samples at four delimitation levels, the direct standardisation method ${ }^{32}$ was used to standardise mean lung function in population types B, C and $\mathrm{D}$, respectively, according to the sex, age and height distribution of population type A (the parent population). ${ }^{23}$

Sex-specific reference values for the median and lower limit of normal (LLN, 5th percentile) lung function were derived from all four populations using quantile regression analysis with age and height as predictors.

Interaction effects between age and height and the four population categories were examined. When plotting the modelled reference values for $\mathrm{FEV}_{1}$ and FVC against age, we standardised height using mean values. All statistical analyses were performed using Stata SE 9.1, Release 9.0 (Stata Statistical Software, StataCorp, 2005).

\section{RESULTS}

Four reference population types

We formed four populations (types) using four delimitation levels (table 1): (A) the parent population with none excluded;

Table 1 Stepwise exclusion of subjects with respiratory diseases, symptoms and smoking history: mean (SD) FEV $1, F V C$ and $\mathrm{FEV}_{1} / \mathrm{FVC}$ at each step

\begin{tabular}{|c|c|c|c|c|}
\hline & $\mathbf{n}$ & FEV $_{1}$ & FVC & $\mathrm{FEV}_{1} / \mathrm{FVC}$ \\
\hline Parent population (A) & 2358 & $3.22(0.94)$ & $4.09(1.14)$ & $0.785(0.067)$ \\
\hline $\begin{array}{l}\text { Subjects without cardinal symptoms (B), } \\
\text { standardised } †\end{array}$ & 1184 & $3.35(0.42)$ & $4.21(0.53)$ & $0.796(0.096)$ \\
\hline \multicolumn{5}{|l|}{$\begin{array}{l}\text { Stepwise exclusion from } \\
\text { population type A to type B }\end{array}$} \\
\hline Not obstructive lung diseases in 1996 & 2188 & $3.28(0.91)^{*}$ & $4.15(1.12)^{*}$ & $0.790(0.059)^{*}$ \\
\hline Not breathlessness grade 4 & 2148 & $3.29(0.91)^{*}$ & $4.16(1.12)^{*}$ & $0.790(0.059)^{*}$ \\
\hline Not breathlessness grade 3 & 2099 & $3.31(0.90)^{*}$ & $4.18(1.11)^{*}$ & $0.790(0.058)^{*}$ \\
\hline Not breathlessness grade 2 & 1886 & $3.36(0.88)^{*}$ & $4.25(1.09)^{*}$ & $0.791(0.057)^{*}$ \\
\hline Not morning cough & 1498 & $3.41(0.89)^{*}$ & $4.29(1.11)^{*}$ & $0.795(0.054)^{*}$ \\
\hline Not breathlessness grade 1 & 1377 & $3.44(0.88)^{*}$ & $4.33(1.10)^{*}$ & $0.796(0.054)$ \\
\hline Not wheeze & 1205 & $3.43(0.88)$ & $4.31(1.09)^{*}$ & $0.797(0.053)^{*}$ \\
\hline Not chronic cough & 1184 & $3.44(0.88)^{*}$ & $4.32(1.09)^{*}$ & $0.797(0.053)$ \\
\hline $\begin{array}{l}\text { Never-smokers without cardinal symptoms } \\
\text { (C), standardised } t\end{array}$ & 539 & $3.39(0.42)$ & $4.25(0.53)$ & $0.799(0.096)$ \\
\hline \multicolumn{5}{|l|}{$\begin{array}{l}\text { Stepwise exclusion from } \\
\text { population type B to type C }\end{array}$} \\
\hline Never-smokers & 539 & $3.43(0.94)$ & $4.28(1.18)$ & $0.801(0.051)^{*}$ \\
\hline \multicolumn{5}{|l|}{$\begin{array}{l}\text { Stepwise exclusion from } \\
\text { population type } C \text { to type } D\end{array}$} \\
\hline Not phlegm & 501 & $3.43(0.94)$ & $4.29(1.17)$ & $0.801(0.051)$ \\
\hline Not attacks of breathlessness & 484 & $3.43(0.93)$ & $4.30(1.17)$ & $0.801(0.052)$ \\
\hline Not day cough & 477 & $3.44(0.93)$ & $4.30(1.16)$ & $0.801(0.051)$ \\
\hline Not infancy lung disease & 471 & $3.44(0.93)$ & $4.30(1.16)$ & $0.801(0.051)$ \\
\hline Not cough with cold & 335 & $3.40(0.95)$ & $4.25(1.18)$ & $0.800(0.053)$ \\
\hline Not woken by breathlessness & 332 & $3.40(0.95)$ & $4.26(1.19)$ & $0.800(0.053)$ \\
\hline Not breathlessness and wheeze & 331 & $3.40(0.95)$ & $4.26(1.19)$ & $0.799(0.053)$ \\
\hline
\end{tabular}


Table 2 Age distribution, occupational exposure to airborne agents and educational level of the four populations

\begin{tabular}{|c|c|c|c|c|}
\hline & $\begin{array}{l}\text { Population A } \\
(n=2358)\end{array}$ & $\begin{array}{l}\text { Population B } \\
\text { ( } \mathrm{n}=1184 \text { ) }\end{array}$ & $\begin{array}{l}\text { Population C } \\
(n=539)\end{array}$ & $\begin{array}{l}\text { Population D } \\
\text { (n=331) }\end{array}$ \\
\hline Men & $1142(48)$ & $595(50)$ & $242(45)$ & $154(47)$ \\
\hline Mean (SD) age (years) & 49.1 (14.4) & $48.1(13.8)$ & $45.2(13.2)$ & $46.3(13.9)$ \\
\hline Age $26-39$ & $350(30)$ & $189(32)$ & $100(41)$ & $61(40)$ \\
\hline Age $40-49$ & $294(26)$ & $160(27)$ & 65 (27) & $36(23)$ \\
\hline Age $50-59$ & 203 (18) & 116 (19) & $36(15)$ & 27 (18) \\
\hline Age $60-69$ & 160 (14) & 77 (13) & $28(12)$ & 19 (12) \\
\hline Age $70-82$ & 135 (12) & $53(9)$ & $13(5)$ & 11 (7) \\
\hline \multicolumn{5}{|l|}{ Occupational exposure } \\
\hline Yes & $706(63)$ & $326(56)$ & $109(46)$ & $64(43)$ \\
\hline \multicolumn{5}{|l|}{ Educational level } \\
\hline Primary & $192(17)$ & $74(13)$ & $15(6)$ & $11(7)$ \\
\hline Secondary & 654 (58) & $332(56)$ & $117(49)$ & 74 (49) \\
\hline University & $283(25)$ & $183(31)$ & 107 (45) & $66(44)$ \\
\hline Women & $1216(52)$ & $589(50)$ & $297(55)$ & $177(53)$ \\
\hline Mean (SD) age (years) & $50.5(15.1)$ & 48.1 (14.2) & $50.9(15.4)$ & $52.5(14.9)$ \\
\hline Age $26-39$ & $335(28)$ & $177(30)$ & $77(26)$ & $37(21)$ \\
\hline Age $40-49$ & $300(25)$ & $163(28)$ & $70(24)$ & $43(24)$ \\
\hline Age $50-59$ & 234 (19) & $127(22)$ & $66(22)$ & $42(24)$ \\
\hline Age $60-69$ & 165 (13) & $61(10)$ & 35 (12) & 24 (14) \\
\hline Age $70-82$ & $182(15)$ & $61(10)$ & $49(16)$ & 31 (17) \\
\hline \multicolumn{5}{|l|}{ Occupational exposure: } \\
\hline \multirow{2}{*}{\multicolumn{5}{|c|}{$\begin{array}{l}\text { Yes } \\
\text { Educational level }\end{array}$}} \\
\hline & & & & \\
\hline Primary & $229(19)$ & $93(16)$ & $46(16)$ & $28(16)$ \\
\hline Secondary & 705 (59) & $326(56)$ & $156(54)$ & $94(54)$ \\
\hline University & $263(22)$ & $162(28)$ & $89(30)$ & $51(30)$ \\
\hline
\end{tabular}

Values are number (\%) unless otherwise indicated.

Population A: parent population; population B: those without the cardinal respiratory symptoms of breathlessness, cough and wheeze; population C: never-smokers without the cardinal respiratory symptoms of breathlessness, cough and wheeze; population $D$ : never-smokers without any respiratory symptoms.

(B) a reference population excluding subjects with self-reported obstructive lung diseases and cardinal respiratory symptoms that led to a statistically significant decrease in lung function; (C) a reference population of never-smokers without obstructive lung diseases or respiratory cardinal symptoms; and (D) a reference population of never-smokers without obstructive lung diseases or any respiratory symptoms (a strict interpretation of the ERS/ATS recommendations). Cardinal respiratory symptoms were breathlessness (grades 1-4), cough (chronic cough and morning cough) and wheeze (table 1). Exclusion of subjects with these symptoms increased standardised mean $\mathrm{FEV}_{1}$ by $0.13 \mathrm{l}$, FVC by $0.12 \mathrm{l}$, and $\mathrm{FEV}_{1} / \mathrm{FVC}$ by 0.011 . Exclusion of ever-smokers led to a further increase in mean lung function. However, exclusion of subjects with minor respiratory symptoms (phlegm, attacks of breathlessness, day cough, infancy lung disease, cough with cold, woken by breathlessness, breathlessness and wheeze) did not influence lung function.

\section{Population characteristics}

The parent population (population A) consisted of 2358 subjects aged 26-82 years, of which $48 \%$ were men. Almost two-thirds of the men (63\%) and one-third of the women (32\%) reported occupational exposure to dust or gas (table 2 ); $25 \%$ of men and $22 \%$ of women had attained university education.

The reference population without obstructive lung diseases or the cardinal respiratory symptoms of breathlessness, cough or

Table 3 Height, weight, $\mathrm{BMI}_{1} \mathrm{FEV}_{1}, \mathrm{FVC}$ and $\mathrm{FEV}_{1} / \mathrm{FVC}$ and respiratory characteristics of the four populations

\begin{tabular}{|c|c|c|c|c|}
\hline & $\begin{array}{l}\text { Population A } \\
\text { (n= 2358) }\end{array}$ & $\begin{array}{l}\text { Population B } \\
\text { ( }=1184)\end{array}$ & $\begin{array}{l}\text { Population C } \\
(n=539)\end{array}$ & $\begin{array}{l}\text { Population D } \\
(n=331)\end{array}$ \\
\hline Men, $\mathrm{n}(\%)$ & $1142(48)$ & $595(50)$ & $242(45)$ & $154(47)$ \\
\hline Height (m) & $1.78(0.07)$ & $1.78(0.07)$ & $1.80(0.07)$ & $1.80(0.07)$ \\
\hline Weight $(\mathrm{kg})$ & 81.9 (12.5) & 82.0 (11.8) & 82.9 (12.0) & $82.2(12.6)$ \\
\hline BMI $\left(\mathrm{kg} / \mathrm{m}^{2}\right)$ & $25.9(3.4)$ & 25.8 (3.2) & 25.7 (3.2) & $25.5(3.4)$ \\
\hline $\mathrm{FEV}_{1}$ (l) & $3.74(0.90)$ & $3.95(0.79)$ & $4.13(0.73)$ & $4.10(0.77)$ \\
\hline FVC (I) & 4.81 (1.02) & $5.01(0.94)$ & $5.20(0.91)$ & $5.17(0.93)$ \\
\hline $\mathrm{FEV}_{1} / \mathrm{FVC}$ & $0.77(0.07)$ & $0.79(0.06)$ & $0.80(0.05)$ & $0.79(0.05)$ \\
\hline Women, n (\%) & $1216(52)$ & $589(50)$ & 297 (55) & 177 (53) \\
\hline Height (m) & $1.65(0.06)$ & $1.65(0.06)$ & $1.65(0.06)$ & $1.64(0.06)$ \\
\hline Weight (kg) & 68.7 (12.8) & 67.2 (12.3) & 67.7 (11.9) & $67.0(11.8)$ \\
\hline BMI $\left(\mathrm{kg} / \mathrm{m}^{2}\right)$ & $25.3(4.5)$ & 24.6 (4.4) & $25.0(4.4)$ & $24.9(4.6)$ \\
\hline $\mathrm{FEV}_{1}$ (l) & $2.73(0.68)$ & $2.92(0.62)$ & $2.85(0.65)$ & $2.79(0.61)$ \\
\hline FVC (I) & $3.42(0.78)$ & $3.61(0.73)$ & $3.53(0.77)$ & $3.46(0.74)$ \\
\hline $\mathrm{FEV}_{1} / \mathrm{FVC}$ & $0.80(0.06)$ & $0.81(0.05)$ & $0.81(0.05)$ & $0.80(0.05)$ \\
\hline
\end{tabular}

Values are mean (SD) unless otherwise indicated.

$\mathrm{BMI}$, body mass index; $\mathrm{FEV}_{1}$, forced expiratory volume in $1 \mathrm{~s} ; \mathrm{FVC}$, forced vital capacity.

Population A: parent population; population B: those without the cardinal respiratory symptoms of breathlessness, cough and wheeze; population C: never-smokers without the cardinal respiratory symptoms of breathlessness, cough and wheeze; population $D$ : never-smokers without any respiratory symptoms. 
wheeze (population type B) consisted of 1184 subjects $(50 \%$ of the parent population). They were slightly younger than the parent population and had generally higher lung function. Fewer reported occupational exposure to dust or gas while more had higher education.

Population types C and D (never-smokers without cardinal respiratory symptoms and never-smokers without any respiratory symptoms) consisted of 539 (23\%) and 331 (14\%) subjects, respectively. The tendency for less occupational exposure and higher education observed in the transition from the parent population to the population without cardinal respiratory symptoms remained stable. The mean age of the men was lower in population types $\mathrm{C}$ and $\mathrm{D}$ while the mean age of the women was higher (table 3). Height and weight were similar in all four population types.

\section{Prediction equations derived from the four population types}

After performing curve-estimation analysis to test for linear, quadratic, cubic, logarithmic and exponential associations, we found that simple linear models with age and height as predictors for $\mathrm{FEV}_{1}$ and FVC gave the best fit for all four population types (see tables El-E4 in the online data supplement available at http://thorax.bmj.com/supplemental). $\mathrm{FEV}_{1} / \mathrm{FVC}$ also had a linear association with age, although the tendency was not statistically significant for men from population types $\mathrm{C}$ and $\mathrm{D}$. The ratio was not associated with height in any of the populations.

For men, reference values for median and LLN lung function had a steeper decline with age for the parent population than for the other three populations $(\mathrm{p}<0.05$, fig 1$)$. Age-related equation difference in $\mathrm{FEV}_{1} / \mathrm{FVC}$ was also significant between population types $B$ and $C(p<0.05$, fig 1$)$. For women, LLN had a steeper decline with age in the parent population $(\mathrm{p}<0.05)$, while the tendency was less clear for median lung function. The population without cardinal respiratory symptoms, the neversmoking population without cardinal respiratory symptoms and the never-smoking population without any respiratory symptoms all produced similar equations for $\mathrm{FEV}_{1}, \mathrm{FVC}$ and $\mathrm{FEV}_{1} / \mathrm{FVC}$ (fig 1).

As expected, the confidence intervals of the regression coefficients for $\mathrm{FEV}_{1}, \mathrm{FVC}$ and $\mathrm{FEV}_{1} / \mathrm{FVC}$ were larger for LLN than for median since the SD for the 5 th percentile is larger than for the 50th percentile (figs E1-E3 in the online supplement available at http://thorax.bmj.com/supplemental). ${ }^{32}$

\section{Prediction coefficients for FEV $_{1}$}

Intercept coefficients from the equations for median and LLN $\mathrm{FEV}_{1}$ did not differ markedly between the four population types, indicating that differences between them are related to age or height associations rather than being constant (fig El in the online supplement available at http://thorax.bmj.com/ supplemental). Height coefficients were higher for men than for women in all four populations. However, they did not differ between the four gender-specific population types $(p>0.05)$.

The decrease in lung function with age was steeper for men than for women in the parent population and in population type B without cardinal respiratory symptoms (fig El in the online supplement available at http://thorax.bmj.com/supplemental). A similar sex difference was not observed in population types $\mathrm{C}$ and $\mathrm{D}$, indicating that decline in $\mathrm{FEV}_{1}$ with age is similar for men and women in these two population types. Equations for median $\mathrm{FEV}_{1}$ in men (not women) and for LLN FEV 1 in both men and women from the parent population had more negative age coefficients than the remaining three population types $(\mathrm{p}<0.05)$.

\section{Prediction coefficients for FVC}

Height coefficients for median FVC were higher overall for men than for women in all the four population types, suggesting that lung function increases more with increasing height in men than in women (fig E2 in the online supplement available at http://thorax.bmj.com/supplemental). The height coefficient was lower for predicted LLN FVC among women in population type $\mathrm{D}$ than among women in the other three populations $(\mathrm{p}<0.05)$.

Age coefficients for FVC were, on the whole, more negative for men than for women, suggesting a steeper decline in FVC with age for men than women. Equations derived for men in the parent population gave more negative age coefficients than equations derived for the other three population types $(p<0.05)$, suggesting that FVC declines more steeply with age in a general male population than in a healthy male population.

\section{Prediction coefficients for $\mathrm{FEV}_{1} / \mathrm{FVC}$}

Height was not a predictor of $\mathrm{FEV}_{1} / \mathrm{FVC}$ for any of the four population types. Age was a significant predictor for median $\mathrm{FEV}_{1} / \mathrm{FVC}$ among both men and women from population types $\mathrm{A}$ and $\mathrm{B}$, and also among women from population types $\mathrm{C}$ and D. With regard to $\mathrm{LLN} \mathrm{FEV}_{1} / \mathrm{FVC}$, age was a significant predictor in men and women in the parent population (type A) and in women in population type B.

There were no significant differences between intercepts from one population type to another.

Age coefficients for median $\mathrm{FEV}_{1} / \mathrm{FVC}$ in men and LLN FEV $/$ / FVC in women were more negative in the parent population than in the population without cardinal respiratory symptoms, suggesting a steeper age-related decline in $\mathrm{FEV}_{1} / \mathrm{FVC}$ in the parent population $(p<0.05$, fig $\mathrm{E} 3$ in the online supplement available at http://thorax.bmj.com/supplemental).

\section{DISCUSSION}

Based on a general population sample of the second phase of the Norwegian Hordaland County Cohort Study, we identified four delimitation levels defining four increasingly healthier and narrower pulmonary reference population types. We derived and compared prediction equations for all four population types and found that self-reported obstructive lung diseases, smoking history, breathlessness, cough and wheeze were optimal exclusion criteria when defining a pulmonary reference population. As expected, predicted lung function values derived from the parent population (population type A) were lower and had a much steeper age-related decline than lung function values derived from the other increasingly healthier population types. Some minor differences were also found between predicted values for the population without the cardinal respiratory symptoms breathlessness, cough and wheeze (population type B) and predicted values for the never-smoking population without the cardinal respiratory symptoms (population type $\mathrm{C}$ ). The never-smoking population without cardinal respiratory symptoms and the never-smoking population without any respiratory symptoms did not differ from each other with regard to lung function equations.

This is the first study to use analysis of the associations between self-reported respiratory symptoms and lung function as a tool to identify simple exclusion criteria for a pulmonary reference population. It is also the first study to compare various definitions of pulmonary reference populations with a general population sample. Such comparison enabled us to examine associations between lung function and the predictors age, height and sex, both in a general population and in increasingly respiratory healthier and narrower reference populations. 

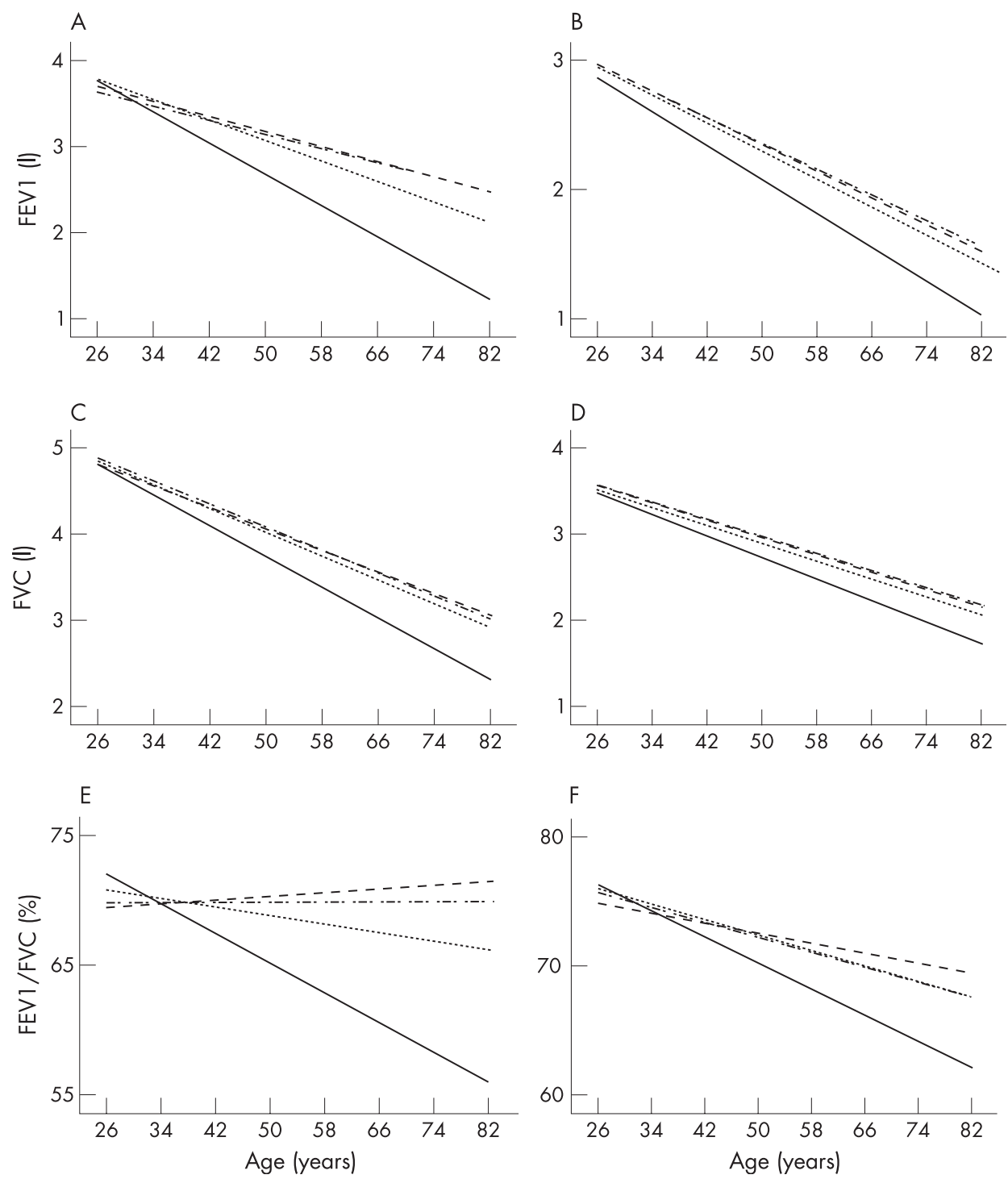

Figure 1 Predicted lower limit of normal for $(A, B)$ forced expiratory volume in $1 \mathrm{~s}\left(\mathrm{FEV}_{1}\right)$, (C, D) forced vital capacity (FVC) and (E, F) $\mathrm{FEV}_{1} / \mathrm{FVC}$ in men of mean height $1.78 \mathrm{~m}$ (A, C, E) and women of mean height $1.65 \mathrm{~m}$ (B, D, F) from four population types: parent population (population type $A, n=2358$, solid line), population without the cardinal respiratory symptoms of breathlessness, cough and wheeze (population type B, $\mathrm{n}=1184$, dashed line), never-smokers without cardinal respiratory symptoms (population type $C, n=539$, dotted line) and never-smokers without any respiratory symptoms (population type $D, n=331$, dashed/dotted line).
A limitation of this study is the age range. The study did not include children and there were only a limited number of elderly subjects, especially men. Furthermore, the study population consisted of Caucasian subjects from an affluent Western country. In clinical practice it is important that reference values are derived from a population that shares such basic characteristics with the patient population. ${ }^{33}$ There is a need for other studies, preferably with a larger proportion of elderly subjects, to assess whether the exclusion criteria identified here are also optimal in other types of populations.

It is possible that the study population was healthier than a general population since all analyses were based on a follow-up study rather than a cross-sectional study. However, a previous report from the Hordaland County Cohort Study showed overall small differences between responders and non-responders in the follow-up survey in 1996-7, and there were no differences in the associations between risk factors such as age and smoking, and respiratory disorders. ${ }^{34}$

Several factors potentially affecting lung function were not examined in the present study-for example, abnormal chest radiographs, diabetes, cardiovascular disease, a history of tuberculosis and malnutrition. It is possible that the presence of such characteristics and diseases might have influenced lung function values in the reference population types. However, a previous study of the same population cohort in 1987 assessed that only 15 of 540 subjects (3\%) had diseases that might affect pulmonary function, ${ }^{14}$ suggesting that such factors are not widespread in a healthy reference population.

The lack of detail in the international recommendations has led to differences in reference population exclusion criteria between studies. The number of exclusion criteria in various published studies presenting spirometric prediction equations varies from 3 to 20 and heavily influences the relative size and health status of the reference populations. ${ }^{5810163536}$ Furthermore, the wording of questions has been shown to influence prevalence rates. ${ }^{26}$ In the present study we have used a questionnaire with questions originating from three previously published and validated respiratory questionnaires. ${ }^{24} 2627$ The NRQ has been used extensively for more than 35 years in Norway. ${ }^{37} 38$ The other two questionnaires have been mostly used in Europe, but parts of them have also been applied in US studies. ${ }^{59}$ To enable comparable lung function prediction equations across studies, it is important to promote uniform exclusion criteria for reference population, with standardised wording of questions. To ensure standardised wording across languages, the methodology of translation and 
back-translation is recommended to enhance questionnaire reliability and validity.

Prediction equations for LLN lung function are used in clinical practice to determine abnormal spirometric rates. If airways obstruction is defined as a $\mathrm{FEV}_{1} / \mathrm{FVC}$ ratio below the LLN, the prevalence would be $5.0 \%$ in the parent population based on the type A reference equations. When implementing LLN reference equations from population types B, C and D, however, the percentage of subjects with airway obstruction in the parent population increased to $9.5 \%, 11.4 \%$ and $10.1 \%$, respectively. Following a stricter definition of airway obstruction as the presence of both $\mathrm{FEV}_{1} / \mathrm{FVC}$ and $\mathrm{FEV}_{1}$ below the LLN, the prevalence would be $2.4 \%$ with type A reference equations, $5.3 \%$ with type $\mathrm{B}$ equations, $6.7 \%$ with type $\mathrm{C}$ equations and $6.1 \%$ with type D equations (results not shown). In any case, the most important difference between abnormal spirometric rates occurs when the cardinal respiratory symptoms of breathlessness, cough and wheeze were excluded from the general population. Some difference was also observed when never-smokers were excluded. However, results from the present study suggest that maintaining reference populations without any respiratory symptoms at all would have no further clinical implications.

In the present study, exclusion of ever-smokers increased observed lung function in the male reference population but decreased lung function in the female reference population. This is probably due to a sex difference in the association between smoking habits and age. While exclusion of eversmokers made the male reference population considerably younger, it made the female reference population older. More young women than elderly women were smokers or exsmokers. Even with the absence of respiratory symptoms, the ageing of the female population when excluding ever-smokers led to a natural decrease in lung function. When adjusting for age in the prediction models, expected lung function was higher after exclusion of never-smokers among both men and women. Furthermore, a previous study from the same population has shown that smoking was a strong predictor for the incidence of chronic obstructive pulmonary disease during a 9 year period for subjects with normal lung function at baseline, ${ }^{40}$ rendering support to the notion that ever-smokers should be excluded from reference populations even if they do not report respiratory symptoms. On the other hand, one could argue that exclusion of ever-smokers from reference populations is not possible in all parts of the world. In some developing countries the proportion of adult never-smoking men may be so small that it would be necessary also to include healthy ever-smokers in reference populations in order to estimate predicted lung function. Future studies should further explore similarities and differences between healthy eversmokers and healthy never-smokers with regard to respiratory status.

Reference population criteria in the present study entailed self-reported respiratory symptoms rather than information on respiratory symptoms obtained by a physician in a clinical examination. Self-administered questionnaires have several advantages over physician-administered interviews. Observational bias affecting answers is not a problem, and the reproducibility for research purposes is better in the absence of a physician's subjective interpretation..$^{41}{ }^{42} \mathrm{~A}$ disadvantage with the use of self-administered questionnaires, however, is that it depends on a literate study population.

Never-smokers without cardinal respiratory symptoms (population type C) and never-smokers without any respiratory symptoms (population type D) constituted $23 \%$ and $14 \%$ of the parent population (population type A), respectively. Whether we used population type $\mathrm{C}$ or $\mathrm{D}$ to derive prediction equations had no implications on the resulting reference values. There are important methodological advantages to keeping the reference population as large as possible, relatively speaking. Narrow reference populations will result in higher statistical uncertainty concerning the reference value estimates than will broader reference populations owing to fewer observations, especially in the older age groups. Rigid exclusion criteria will lead to selection bias and skewed age distributions. More elderly subjects than younger subjects suffer from respiratory symptoms, so older age groups will be under-represented in a reference population based on rigid exclusion criteria. This, in turn, may influence the association between age and lung function as observed in the present study where the association between age and $\mathrm{FEV}_{1} / \mathrm{FVC}$ did not reach statistical significance in the healthiest population types. There were only 13 neversmoking men in the 70-82 year age group without cardinal symptoms (population type C) in the present study. A larger proportion of elderly subjects in the reference population would perhaps lead to a significant reduction in $\mathrm{FEV}_{1} / \mathrm{FVC}$ with age, more in line with what has been observed in other studies. ${ }^{1}$

A similar selection bias was also observed with occupational exposure to dust or gas. After exclusion of cardinal respiratory symptoms, additional sex-stratified analyses showed no difference in lung function between persons who had been occupationally exposed to dust or gas and those who had never been subjected to such exposure ( $\mathrm{p}>0.05$, results not shown). However, the size of the reference populations would have decreased by $57 \%$ for men and $27 \%$ for women if all occupationally exposed subjects were excluded.

Subjects with respiratory symptoms were excluded in a stepwise order based on both existing clinical and methodological considerations. ${ }^{19-21}$ The symptom whose exclusion led to the largest increase in mean lung function was excluded first. It could be argued that the order of exclusion influenced the resulting reference population exclusion criteria. However, additional analyses in which the exclusion order was changed among the seven cardinal respiratory symptoms (breathlessness grades 1-4, morning cough, chronic cough and wheeze) gave the same overall results regarding statistical significance and change in lung function. Breathlessness grades $1-4$ and morning cough also remained significant if ever-smokers were excluded first $(\mathrm{p}<0.05$, results not shown).

Exclusion of all ever-smokers with obstructive lung diseases or any respiratory symptoms in the present study left only $14 \%$ of the total population. However, excluding only ever-smokers with obstructive lung diseases or the cardinal respiratory symptoms of breathlessness (grades 1-4), cough (morning cough and chronic cough) and wheeze resulted in a substantially larger and valid reference population. We believe that these exclusion criteria will be feasible and sufficient to enable derivation of prediction equations comparable across studies. We recommend testing the exclusion criteria with identical wording in both existing and future larger populations for further validation. The results from the present study should be included in the future discussion of a more detailed and standardised international definition of pulmonary reference populations.

\section{ACKNOWLEDGEMENTS}

The authors are indebted to the Centre for Clinical Research at Haukeland University Hospital, to respiratory laboratory technician Lene Svendsen, statistician Roy Miodini Nilsen, and to Professor Paul Enright for valuable comments.

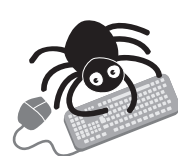

Further information is given in the Appendix, tables E1-E4 and figs E1-E3 available online at http:// thorax.bmi.com/supplemental. 


\section{Authors' affiliations}

Ane Johannessen, Ernst R Omenaas, Centre for Clinical Research, Haukeland University Hospital, Bergen and Institute of Medicine, University of Bergen, Norway

Geir Egil Eide, Centre for Clinical Research, Haukeland University Hospital, Bergen and Section for Epidemiology and Medical Statistics, Department of Public Health and Primary Health Care, University of Bergen, Norway Per S Bakke, Amund Gulsvik, Department of Thoracic Medicine,

Haukeland University Hospital, Bergen and Institute of Medicine, University of Bergen, Norway

The Hordaland County Cohort Study was funded from the Royal Norwegian Council for Scientific and Industrial Research and the Norwegian Research Council.

Competing interests: None declared.

\section{REFERENCES}

1 American Thoracic Society. Lung function testing: selection of reference values and interpretative strategies. Am Rev Respir Dis 1991;144:1202-18.

2 Pellegrino R, Viegi G, Brusasco V, et al. Interpretative strategies for lung function tests. Eur Respir J 2005;26:948-68.

3 Johannessen A, Lehmann S, Omenaas ER, et al. Post-bronchodilator spirometry reference values in adults and implications for disease management. Am J Respir Crit Care Med 2006;173:1316-25.

4 Quanjer P, Tammeling G, Cotes J, et al. Lung volumes and forced ventilatory flows. Report Working Party Standardisation of lung function tests, European Community for Steel and Coal. Official statement of the European Respiratory Society. Eur Respir J 1993;6(Suppl 16):5-40.

5 Hankinson JL, Odencrantz JR, Fedan KB. Spirometric reference values from a sample of the general U.S. population. Am J Respir Crit Care Med 1999;159:179-87.

6 Falaschetti E, Laiho J, Primatesta $\mathrm{P}$, et al. Prediction equations for normal and low lung function from the Health Survey for England. Eur Respir J 2004;23:456-63.

7 Knudson RJ, Slatin RC, Lebowitz MD, et al. The maximal expiratory flow-volume curve. Normal standards, variability, and effects of age. Am Rev Respir Dis 1976;1 13:587-600.

8 Dockery DW, Ware JH, Ferris BG Jr, et al. Distribution of forced expiratory volume in one second and forced vital capacity in healthy, white, adult neversmokers in six U.S. cities. Am Rev Respir Dis 1985;131:511-20.

9 Roca J, Sanchis J, Agusti-Vidal A, et al. Spirometric reference values from a Mediterranean population. Bull Eur Physiopathol Respir 1986;22:217-24.

10 Enright PL, Kronmal RA, Higgins M, et al. Spirometry reference values for women and men 65 to 85 years of age. Cardiovascular Health Study. Am Rev Respir Dis 1993; 147:125-33.

11 Glindmeyer HW, Lefante JJ, McColloster C, et al. Blue-collar normative spirometric values for Caucasian and African-American men and women aged 18 to 65. Am J Respir Crit Care Med 1995;151:412-22.

12 Brandli O, Schindler C, Kunzli N, et al. Lung function in healthy never smoking adults: reference values and lower limits of normal of a Swiss population. Thorax 1996:51:277-83.

13 McDonnell WF, Enright PL, Abbey DE, et al. Spirometric reference equations for older adults. Respir Med 1998;92:914-21.

14 Gulsvik A, Tosteson T, Bakke $\mathrm{P}$, et al. Expiratory and inspiratory forced vita capacity and one-second forced volume in asymptomatic never-smokers in Norway. Clin Physiol 2001;21:648-60.

15 Langhammer A, Johnsen R, Gulsvik A, et al. Forced spirometry reference values for Norwegian adults: the bronchial obstruction in Nord-Trondelag study. Eur Respir J 2001;18:770-9.

16 Garcia-Rio F, Pino JM, Dorgham A, et al. Spirometric reference equations for European females and males aged 65-85 yrs. Eur Respir J 2004;24:397-405.
17 Pistelli F, Bottai $M$, Viegi G, et al. Smooth reference equations for slow vital capacity and flow-volume curve indexes. Am J Respir Crit Care Med 2000;161:899-905.

18 Gulsvik A, Bakke P, Humerfelt S, et al. Measurement of respiratory symptoms and sample size to detect a given difference between treatment groups in obstructive lung disease. Eur Respir Rev 1991;1(Suppl 5):436-43.

19 Sunyer J, Basagana X, Roca J, et al. Relations between respiratory symptoms and spirometric values in young adults: the European Community Respiratory Health Study. Respir Med 2004;98:1025-33.

20 Jaakkola MS, Jaakkola JJ, Ernst $P$, et al. Respiratory symptoms in young adults should not be overlooked. Am Rev Respir Dis 1993;147:359-66.

21 Sherman CB, Xu X, Speizer FE, et al. Longitudinal lung function decline in subjects with respiratory symptoms. Am Rev Respir Dis 1992;146:855-9.

22 Eagan TM, Gulsvik A, Eide GE, et al. Occupational airborne exposure and the incidence of respiratory symptoms and asthma. Am J Respir Crit Care Med 2002; 166:933-8

23 Johannessen A, Omenaas ER, Bakke PS, et al. Implications of reversibility testing on prevalence and risk factors for chronic obstructive pulmonary disease: a community study. Thorax 2005;60:842-7.

24 Medical Research Council Committee on the Aetiology of Chronic Bronchitis. Standardised questionnaire on respiratory symptoms. BMJ 1960;2:1665.

25 Gulsvik A. Obstructive lung disease in an urban population, Thesis.Reprografisk Industri A/S, 1979.

26 Brøgger J, Bakke P, Gulsvik A. Comparison of respiratory symptoms questionnaires. Int J Tuberc Lung Dis 2000;4:83-90.

27 Burney PG, Luczynska C, Chinn S, et al. The European Community Respiratory Health Survey. Eur Respir J 1994;7:954-60.

28 European Community Respiratory Health Survey. Questionnaires, protocols and instructions 2006

29 Zijistra W, Buursma A, Zwart A. Performance of an automated six-wavelength photometer (radiometer OSM 3) for routine measurement of hemoglobin derivatives. Clin Chem 1988;34:149-52

30 Omenaas $E$, Bakke $P$, Haukenes $G$, et al. Respiratory virus antibodies in adults of a Norwegian community: prevalences and risk factors. Int J Epidemiol 1995;24:223-31

31 American Thoracic Society. Standardization of spirometry, 1994 update. Am J Respir Crit Care Med 1995;152:1107-36.

32 Armitage P, Berry G, Matthews JNS. Statistical methods in medical research, 4th ed. Oxford: Blackwell Science, 2002:660-7.

33 Kerstiens HA, Rijcken B, Schouten JP, et al. Decline of FEV 1 by age and smoking status: facts, figures, and fallacies. Thorax 1997;52:820-7.

34 Eagan TM, Eide GE, Gulsvik A, et al. Nonresponse in a community cohort study: predictors and consequences for exposure-disease associations. J Clin Epidemiol 2002;55:775-81.

35 Roca J, Burgos F, Sunyer J, et al. References values for forced spirometry. Group of the European Community Respiratory Health Survey. Eur Respir J 1998;1 1:1354-62.

36 Crapo RO, Morris AH, Gardner RM. Reference spirometric values using techniques and equipment that meet ATS recommendations. Am Rev Respir Dis 1981;123:659-64.

37 Gulsvik A. Prevalence and manifestations of obstructive lung disease in the city of Oslo. Scand J Respir Dis 1979;60:257-66.

38 Bakke P, Eide G, Hanoa R, et al. Occupational dust or gas exposure and prevalence of respiratory symptoms and asthma in a general population. Eur Respir J 1991;4:273-8.

39 Buist AS, Vollmer WW, Sullivan SD, et al. The Burden of Obstructive Lung Disease Initiative (BOLD): rationale and design. COPD 2005;2:277-83.

40 Johannessen A, Omenaas E, Bakke P, et al. Incidence of GOLD-defined chronic obstructive pulmonary disease in a general adult population. Int J Tuberc Lung Dis 2005;9:926-32

41 Cochrane AL, Chapman PJ, Oldham PD. Observers' errors in taking medical histories. Lancet 1951;1:1007-9.

42 Kongerud J, Vale JR, Aalen OO. Questionnaire reliability and validity for aluminum potroom workers. Scand J Work Environ Health 1989;15:364-70.

\section{International Forum on Quality and Safety in Health Care}

23-25 April 2008

Le Palais des Congrès de Paris

Call for Abstracts: Submission deadline 3 October 2007

Why submit an abstract?

- Your achievement showcased to key international opinion leaders

- Communicate your organisation's work

- Enhance your organisation's profile

- Network with others in your area/field

- Share your success, learn from your failures

For more details and to submit your abstract online visit internationalforum.bmj.com 